\title{
PARTICIPAR ESTÁ NA MODA: UMA ABORDAGEM PSICOSSOCIAL DOS ORÇAMENTOS PARTICIPATIVOS
}

\author{
PARTICIPAR ESTÁ DE MODA: UN ENFOOUE PSICOSOCIAL DE LOS \\ PRESUPUESTOS PARTICIPATIVOS \\ PARTICIPATION IS TRENDY: A SOCIAL PSYCHOLOGICAL APPROACH TO \\ THE PARTICIPATORY BUDGET
}

http://dx.doi.org/10.1590/1807-0310/2018v30165726

Margarida Santos, Susana Batel e Maria Eduarda Gonçalves

Instituto Universitário de Lisboa (ISCTE-IUL), Lisboa, Portugal

\begin{abstract}
RESUMO
Autores têm apontado para como os processos de participação institucionalizados poderão não ser verdadeiramente participativos. Este estudo analisa factores estruturais condicionantes destes processos, tendencialmente esquecidos nos estudos sobre a participação no âmbito da Psicologia Social, através de análise exploratória das sessões de Orçamento Participativo (OP) em três municípios em Portugal. Partindo de uma perspectiva etnográfica, procurámos perceber que factores estão relacionados com os modelos de $\mathrm{OP}$ e em que medida os contextos social, cultural e político de cada município poderão explicar as diferenças verificadas na participação local; em que medida a organização espacial das sessões, os recursos utilizados e o tipo de comunicação poderão estar associados às mesmas. As análises sugerem uma relação complexa entre a natureza mais ou menos deliberativa/consultiva do procedimento e o nível de participação, demonstrando que a retórica institucional participativa utilizada pelos decisores nem sempre corresponde a práticas mais ou menos participativas por parte dos cidadãos.
\end{abstract}

Palavras-chave: participação institucional; contexto social e cultural; comunicação.

\section{RESUMEN}

Autores han señalado cómo los procesos de participación institucionalizados pueden no ser verdaderamente participativos. Se analizam factores estructurales condicionantes de estos procesos, tendencialmente olvidados en los estudios sobre la participación en la Psicología Social, a través de análisis exploratorio de las sesiones de Presupuesto Participativo (PP) en tres municipios en Portugal. A partir de una perspectiva etnográfica, intentamos percibir qué factores están relacionados con los modelos de PP y en qué medida los contextos social, cultural y político de cada municipio pueden explicar las diferencias en la participación local; en qué medida la organización espacial de las sesiones, los recursos utilizados y el tipo de comunicación podrán estar asociados a las mismas. Los análisis sugieren una relación compleja entre la naturaleza más o menos deliberativa/consultiva del procedimiento y el nivel de participación, donde la retórica institucional participativa utilizada por los decisores no siempre corresponde a prácticas más o menos participativas por parte de los ciudadanos.

Palabras clave: participación institucional; contexto social y cultural; comunicación.

\begin{abstract}
Institutionalized participatory processes may not be truly participative. This study aims to analyze structural factors underlying participation, often neglected by social psychology. An exploratory study was carried out on participatory budgeting sessions in three municipalities in Portugal. From an ethnographic perspective, we have compared contextual factors related to different participatory budgeting models; differences in citizens' participation which may be attributed to the social, cultural and political contexts of each municipality; and how the spatial organization, the resources applied and the type of communication used in the different budgeting sessions may possibly shape the ways different agents interact. Results suggest that there is a complex relation between the deliberative/consultative natures of the participatory budgeting and the level of the citizens' participation, showing that the participatory institutional rhetoric used by policymakers does not always correspond to citizens' participatory practices.
\end{abstract}

Keywords: institutionalized participation; social and cultural context; communication. 


\section{Introdução}

A partir da segunda metade do século XX começam a surgir, sobretudo no mundo ocidental, novas formas de ação coletiva associadas à defesa dos direitos e da identidade de determinados grupos, como os movimentos negros, ambientalistas e feministas (Nunes, 2011). Estes novos movimentos sociais e o próprio contexto do pós-II guerra mundial contribuíram para que o envolvimento dos cidadãos na tomada de decisão ganhasse expressão em tratados e leis, recomendando políticos, decisores e empresas a envolverem os cidadãos nos processos de tomada de decisão que os afectam (Agenda 21, 1992; Knudsen et al., 2015). Esta institucionalização da participação tem permitido, sobretudo nos últimos anos, o desenvolvimento de uma retórica institucional, por parte de decisores e de algumas forças políticas, de que os processos de decisão já são realizados com a participação dos cidadãos (Barry, Ellis, \& Robinson, 2008), caso os próprios queiram participar (Castro \& Batel, 2008). No entanto, particularmente no âmbito dos estudos da ciência e da tecnologia e das ciências políticas (Barnett, Burningham, Walker, \& Cass, 2012; Mouffe, 2013), tem-se vindo a demonstrar que este discurso, embora pareça garantir a participação dos/as cidadãos/ãs, expressa uma concepção tokenista de envolvimento, reproduzindo as relações de poder tradicionais entre os designados sistemas técnico-políticos e os leigos (Barry et al., 2008; Batel \& Castro, 2009; Gonçalves \& Castro, 2003; Rowe \& Frewer, 2004). Neste sentido, alguns dos estudos sobre a participação parecem, por vezes, contribuir para perpetuar modelos de participação "light" (Rowe \& Frewer, 2004; Serapioni \& Duxbury, 2012), evitando frequentemente a discussão e análise do papel concomitante de factores estruturais, ideológicos e contextuais-relacionais. Exemplo disso é a literatura mais corrente da Psicologia Social sobre acção coletiva, sobretudo baseada em modelos individualistas e positivistas (para uma revisão ver Batel \& Castro, 2015), que tende a negligenciar o papel que o actual modelo de desenvolvimento social, político e económico assume nas dinâmicas entre os grupos sociais (Elcheroth, Doise, \& Reicher, 2011). Por outro lado, estes estudos têm estado essencialmente focados na análise da participação das/os cidadãs/ãos em movimentos sociais (van Zomeren, Postmes, \& Spears, 2008), negligenciando a participação no quadro de formas mais institucionalizadas de "acção colectiva".

Este trabalho pretende contribuir para uma melhor compreensão dos factores estruturais, ideológicos e contextuais-relacionais associados à ausência de participação institucional das/os cidadãs/ãos com base numa análise exploratória do funcionamento dos Orçamentos Participativos (OP), uma forma institucionalizada de participação. Os OP são paradigmáticos do paradoxo que acabámos de anunciar - apesar de serem apresentados como um modelo da institucionalização da participação, têm tido uma implantação difícil no território, com interrupções sucessivas e marcados por uma fraca adesão das comunidades locais, especificamente em Portugal (Dias, 2013). Centrando a nossa investigação no estudo de caso dos OP, em Portugal, pretendemos contribuir não só para a literatura da Psicologia Social e Ambiental, analisando um processo de participação institucionalizado, mas também, de uma maneira mais geral, para o estudo dos processos de participação, explorando simultaneamente como as dimensões contextuais-relacionais envolvendo os sistemas técnico-político e leigo reflectem dimensões culturais e institucionais da participação, especificamente, relações de poder assimétricas. Começaremos por discutir a forma como, no âmbito da Psicologia Social e Ambiental, tem sido acompanhado este desenvolvimento e as suas principais limitações face ao estudo da participação institucional. Finalmente, discutiremos em que medida outras perspectivas, provindas da Psicologia Social e de outras ciências sociais, podem contribuir para ultrapassar essas limitações e ajudar a uma melhor compreensão da (in)existência da participação. Esta proposta será empiricamente examinada com base num estudo exploratório por observação de três OP em Portugal.

\section{Psicologia social e ambiental e a participação institucional}

A maioria das teorias da Psicologia Social, nomeadamentecombase norte-americana e/ou europeia (ver Nelson \& Prilletensky, 2005), tendem a focar-se na compreensão dos determinantes da participação em diferentes formas de acção colectiva ou movimentos sociais, com base numa epistemologia cognitivista e individualista dos mesmos, negligenciando nas suas análises factores mais estruturais e ideológicos (para uma revisão ver Batel \& Castro, 2015; Elcheroth et al., 2011). Ainda que alguns estudos analisem factores como a ideologia e o contexto (van Stekelenburg, Klandermans, \& van Dijk, 2009), tendem a estudálos como características estanques, que accionam respostas automáticas nos indivíduos (Batel \& Castro, 2015), como se esses factores fossem externos e não coconstruídos pelos indivíduos e grupos. Além disso, os estudos da Psicologia Social sobre a participação incidem, maioritariamente, sobre dinâmicas intergrupais no plano da acção colectiva nos movimentos sociais (van Stekelenbur et al., 
2009; van Zomeren et al., 2008), sendo minoritários ${ }^{1}$ os que analisam processos de tomada de decisão, particularmente, participação institucional. Por esse motivo, são igualmente poucas as análises sobre a relação entre os actores sociais intervenientes em arranjos institucionais de participação. A "importação" destas teorias da Psicologia Social para a Psicologia Ambiental veio trazer uma abordagem mais centrada no envolvimento de cidadãos em processos de tomada de decisão, bem como na forma como estes, conduzidos normalmente por grupos de peritos, excluem à partida os potenciais contributos dos públicos afectados (Batel \& Devine-Wright, 2015; Lennon \& Scott, 2015). De facto, são vários os autores que, ao analisar a reacção das/os cidadãs/ãos face a decisões que os afectam, mas das quais são excluídos, evidenciam a representação negativa do sistema técnico-político a respeito do público, rotulado como emocional ou irracional, insuficientemente informado e hostil aos avanços tecnológicos, o que leva técnicos e decisores a desqualificarem as posições do público (Barnett et al., 2012; Batel \& Devine-Wright, 2015). Por outro lado, a percepção de que alguns destes processos não são verdadeiramente participativos, pois os/as cidadãos/ãs não exercem real poder de influência, tem contribuído para o seu afastamento e consequente resistência a certas decisões (Knudsen et al., 2015). Este tipo de estudos veio permitir olhar para os contextos da participação, em particular, para a relação, geralmente desigual, que se estabelece entre os intervenientes (ver Barry et al, 2008; Lennon \& Scott, 2015). É sobre esta nova abordagem crítica da participação pública em processos institucionais que iremos falar de seguida.

\section{Novas perspectivas no estudo da participação - outras ciências sociais}

A literatura tem apontado a multiplicação de ferramentas governativas, aparentementeparticipativas, como reforço da confiança nas instituições do sistema democrático e nos seus representantes (Cass, 2006). No entanto, alguns autores têm defendido que quem promove as oportunidades de participação - como os processos de orçamento participativo - parece inspirar-se na ideia de que os cidadãos necessitam de orientação para tomar a melhor decisão (Thaler \& Sunstein, 2008), a que a literatura tem designado de soft-paternalismo (Colander \& Qui Lin Chong, 2009), motor de abrandamento social (Moir \& Leishon, 2013). No mesmo sentido, assiste-se à tendência de evitar, no debate público, a disputa ideológica e a emergência das diferenças fundamentais, ignorando assimetrias de poder inerentes à própria democracia (Mouffe, 2013; Swyngedouw, 2010). Esta identificação de processos participativos do tipo institucional com políticas governativas do tipo soft-paternalistas (Moir \& Leishon, 2013) não parece, portanto, promover processos verdadeiramente participativos, no sentido de os cidadãos terem real poder de influência na tomada de decisão (Arnstein, 1969). Tal tem mostrado que os sistemas técnico-políticos - que têm o poder de definir quem participa, como participa e quando participa (Knudsen et al., 2015) - tendem a não valorizar as experiências do público em geral, impedindo o contributo de outros conhecimentos o que, no limite, dificulta a geração de epistemologias alternativas (Santos, 1998).

A análise das representações dos sistemas técnico-políticos sobre a participação dos cidadãos tem identificado várias estratégias retóricas utilizadas por estes como instrumentais para a negociação e resistência à mudança (e.g., Barry et al., 2008; Batel \& Castro, 2009, 2015; Lennon \& Scott, 2015). São exemplos a distinção entre a norma e a prática da participação - e.g., sim, a participação é importante, mas neste caso nós é que sabemos (Batel \& DevineWright, 2015); a distinção nós vs. eles, para acentuar as diferenças entre os grupos (Castro \& Batel, 2008); ou a utilização estratégica do ethos (relativo à capacidade de influência de quem profere o discurso), do pathos (relativo à proximidade e emoção que se consegue desencadear por via do discurso produzido) e do $\log o s$ (relativo à demonstração da racionalidade do próprio argumento discursivo) (Barry et al., 2008; Lenonn \& Scott, 2015). Mais negligenciada tem sido a análise de como a relação contextual e a comunicação entre esses sistemas afectam e são afectadas por essas representações e pelas relações de dominação existentes (Batel \& Devine-Wright, 2015). Em particular, partindo da Psicologia Social, são raros os estudos entre a articulação entre o nível contextual e relacional da (não) participação dos cidadãos nos processos de tomada de decisão, e o nível estrutural e ideológico dessa (não) participação, bem como, e de forma relacionada, o modo como isso é influenciado e reflectido em práticas discursivas e práticas materiais (Latour, 2005; Marres, 2012). A presente pesquisa pretende precisamente contribuir para ultrapassar estas lacunas. Especificamente, propomos (a) comparar diferentes orçamentos participativos (OP) em contextos sociais e políticos igualmente distintos, tendo em vista perceber que factores estão relacionados com a decisão dos governos locais de implementar os OP e se existem diferenças entre os contextos em análise e o tipo de participação das populações locais nesses processos; e (b) observar de que forma a relação entre os políticos eleitos pela população, técnicos camarários e os cidadãos se traduz na organização 
espacial das sessões dos OP, nos recursos utilizados e na forma como comunicam entre si.

\section{Contexto, procedimento e participantes}

\section{Contexto: o orçamento participativo em Portugal}

Nos últimos anos, os processos deliberativos têm assumido uma preponderância crescente na aproximação dos decisores políticos aos cidadãos (Serapioni \& Duxbury, 2012). À escala global, têm vindo a ser consagrados legalmente procedimentos de participação pública em diversas áreas, objecto de posteriores apropriações em função dos contextos histórico-culturais, bem como dos contextos regionais específicos (Batel \& Devine-Wright, 2015). Os OP em Portugal são exemplo disso, tendo surgido nos anos oitenta em Porto Alegre, no Brasil, e chegado a Portugal depois de 2000. Actualmente, constituem instrumentos de governação disseminados um pouco por todo o mundo, apresentando-se como uma nova forma de governação assente na participação dos cidadãos não eleitos na definição das políticas públicas e das prioridades para o território (Dias, 2013). Apesar da génese deliberativa do processo de OP, em Portugal, as experiências de OP começaram por ser maioritariamente de carácter consultivo, cabendo a decisão final aos executivos municipais (Allegretti \& Dias, 2009). Esta realidade começou a mudar de há dez anos para cá, verificando-se um número crescente de processos deliberativos nos quais os cidadãos apresentam e votam os projectos para execução (Allegretti \& Dias, 2009). No entanto, a categorização formal a priori dos OP, como consultivos ou deliberativos, não significa, por um lado, que o tipo de participação e interacção que efectivamente se materializa corresponda a essa categorização, e, por outro, que a cada categoria estejam associados processos mais ou menos participativos. Sendo esta, precisamente, uma das questões que pretendemos analisar, no contexto de cada sessão observada, olhamos em particular para as interacções que se estabelecem entre o grupo dos tradicionais decisores, representado quer pelos membros do executivo camarário, presidente e/ ou vereadores, que designamos de "políticos", no sentido em que foram objectivo de eleição por parte dos habitantes locais; quer pelos funcionários camarários, não eleitos e com funções técnicas no seio do município, que designamos de "técnicos"; quer por todos os cidadãos participantes nas sessões públicas de participação, sem relação aparente com a Câmara Municipal, em representação individual ou de uma organização local, que designamos de "cidadãos".

\section{Estudos de caso e procedimento}

Uma das principais conquistas da Revolução Portuguesa de 1974 é o estabelecimento do chamado Poder Local Democrático, consagrado na Constituição Portuguesa de 1976. O Poder Local português assenta em três unidades político-administrativas: câmara municipal, assembleia municipal (308, no total, correspondendo ao número de municípios portugueses) e assembleia de freguesia (3092, no total, constituindo a unidade político-administrativa portuguesa mais pequena). Do ponto de vista administrativo, é igualmente importante referir a organização do país nos seus 18 Distritos, designação frequentemente utilizada para fins estatísticos, geográficos e económicos. De facto, em Portugal, o OP tem sido, maioritariamente, desenvolvido ao nível das câmaras municipais e das assembleias de freguesia. Por constituírem processos institucionalizados a nível municipal, e com maior impacto junto das populações locais, optámos por analisar os OP promovidos por câmaras municipais. Para o efeito, conduzimos um estudo quasi-etnográfico (Pina-Cabral, 2009), com base na observação de várias sessões dos OP. Embora não se tenha tratado de uma observação participante, coube à primeira autora a negociação prévia com os responsáveis para a observação das sessões de participação, bem como a presença nessas mesmas sessões para realização da observação, criando redes de contacto nos diferentes contextos em estudo que, necessariamente, foram contribuindo para modelar a observação e o curso da própria investigação (Zuber, 2010). Foram escolhidos como estudos de caso os OP das Câmaras Municipais de Palmela, Cascais e Torres Vedras com base nos seguintes critérios: serem municípios com diferentes experiências de OP, quer do ponto de vista do funcionamento do processo - modelo deliberativo, decisão cabe às populações, versus modelo consultivo, decisão cabe ao executivo -, quer do ponto de vista da antiguidade, procurando diversidade nos anos de experiência das Câmaras; terem executivos camarários com diferentes orientações político-partidárias, abrangendo todas as forças políticas com funções de presidência de Câmara no país (exceptuando os/as eleitos/as por movimentos de cidadãos/ãs), procurando diferenças nas motivações políticas subjacentes ao processo; e o facto de ocorrerem em contextos territoriais diferentes, nomeadamente, ao nível da localização geográfica e da dimensão populacional, factores que influenciam a própria política orçamental municipal - estes critérios permitem-nos uma visão geral sobre as diferenças ao nível do contexto social, cultural e político em que ocorrem os $\mathrm{OP}$ em estudo (ver Tabela 1). 
Tabela 1. Contexto político de cada orçamento participativo

\begin{tabular}{|c|c|c|c|}
\hline & Palmela & Cascais & $\begin{array}{l}\text { Torres } \\
\text { Vedras } \\
\end{array}$ \\
\hline $\begin{array}{c}\text { Orientação } \\
\text { político- } \\
\text { partidária }\end{array}$ & \begin{tabular}{|c|} 
CDU \\
(Coligação \\
Democrática \\
Unitária: \\
Partido \\
Comunista \\
Português \\
e Partido \\
Ecologista “Os \\
Verdes") - \\
Esquerda \\
\end{tabular} & $\begin{array}{l}\text { Coligação } \\
\text { Viva Cascais } \\
\text { (Partido } \\
\text { Social- } \\
\text { Democrata } \\
\text { e Partido } \\
\text { Popular) - } \\
\text { Direita }\end{array}$ & $\begin{array}{l}\text { PS (Partido } \\
\text { Socialista) } \\
\text { - Centro- } \\
\text { Esquerda }\end{array}$ \\
\hline $\begin{array}{c}\text { Autoclassificação } \\
\text { do modelo de } \\
\text { decisão }\end{array}$ & Consultivo & Deliberativo & Deliberativo \\
\hline Antiguidade & $12^{\mathrm{a}}$ edição & $5^{\mathrm{a}}$ edição & $1^{\mathrm{a}}$ edição \\
\hline N..$^{\circ}$ de habitantes & 62831 & 79465 & 206479 \\
\hline
\end{tabular}

A observação das sessões públicas de participação foi feita com recurso a uma matriz de observação construída para o efeito que, à luz dos objectivos definidos e inspirada nos trabalhos de observação de orçamentos participativos, contém seis dimensões de observação: a caracterização do espaço (e.g., formato de sala de aula); o início dos trabalhos (e.g., abertura formal da sessão); a interacção durante a sessão (e.g., diálogo entre técnicos e cidadãos); o papel dos políticos (e.g., tempo de intervenção curto); o papel dos técnicos (e.g., intervêm ao longo da sessão); e o tipo de participação do/a cidadão/ã (e.g., faz uma reclamação). Para proceder à validação da matriz de observação, recorreu-se ao método do acordo interobservadores (Martins \& Machado, 2006) - já que Bakeman (2000) defende que o acordo entre avaliadores parece ser uma condição sine qua non da investigação observacional - na primeira sessão observada, tendo havido $85 \%$ de acordo, i.e., de semelhança nas observações registadas por ambas. Foram feitas observações em duas sessões públicas de participação por município $(N=6)$, potencialmente mais populosas, tendo sido realizadas entre Abril e Junho de 2015, decorrendo sempre em dias de semana em horário pós-laboral, à excepção da segunda sessão pública no município de Cascais, que decorreu num sábado durante a tarde. Procedeu-se ainda a um levantamento documental e análise relativamente ao contexto sócio-histórico e político de cada Câmara Municipal, nomeadamente na sua relação com o OP, para permitir a contextualização da análise da observação das diferentes sessões.

\section{Análise e discussão}

Procurámos fazer uma breve introdução ao contexto social e político de cada região, no sentido de perceber de que forma algumas características estruturais dos municípios em análise estão relacionadas com o modelo de OP implementado; na Tabela 1 apresentam-se os indicadores pelos quais nos guiámos nessa caracterização. Procurámos também, como indicado anteriormente, analisar dimensões contextuais-relacionais através do estudo por observação, como seja a relação entre a estruturação do espaço físico das sessões e o modelo de OP adoptado ou em que medida o tipo de interacção entre os diferentes intervenientes se relaciona com o tipo de participação que acontece nas sessões (Tabela 2).

Tabela 2. Caracterização geral das sessões de participação pública

\begin{tabular}{|c|c|c|c|}
\hline & \begin{tabular}{|cc|}
\multicolumn{2}{|c|}{ Palmela } \\
Sessão Sessão \\
1 & 2 \\
\end{tabular} & \begin{tabular}{cc}
\multicolumn{2}{c}{ Cascais } \\
Sessão Sessão \\
1 & 2 \\
\end{tabular} & \begin{tabular}{cc}
\multicolumn{2}{c}{ Torres Vedras } \\
Sessão & Sessão \\
1 & 2 \\
\end{tabular} \\
\hline $\begin{array}{c}\text { Disposição } \\
\text { da sessão }\end{array}$ & $\begin{array}{l}\text { Tipo "sala de } \\
\text { aula" }\end{array}$ & $\begin{array}{r}\text { Mesas de dis } \\
\text { pess }\end{array}$ & $\begin{array}{l}\text { cussão (cerca de } 8 \\
\text { oa/mesa) }\end{array}$ \\
\hline $\begin{array}{l}\text { Comida/ } \\
\text { bebida }\end{array}$ & - & $\begin{array}{l}\text { Mesa à parte } \\
\text { com bolos e } \\
\text { bebidas }\end{array}$ & $\begin{array}{c}\text { Água e rebuçados } \\
\text { espalhados pelas } \\
\text { mesas }\end{array}$ \\
\hline Materiais & $\begin{array}{c}\text { Inquérito } \\
\text { da CM p/ } \\
\text { preenchimento }\end{array}$ & $\begin{array}{l}\text { Pasta com as } \\
\text { folhas para } \\
\text { preenchimento } \\
\text { das propostas } \\
\text { e votação } \\
\end{array}$ & $\begin{array}{c}\text { Pasta com as folhas } \\
\text { para preenchimento } \\
\text { das propostas e } \\
\text { votação }\end{array}$ \\
\hline $\begin{array}{l}\text { Abertura } \\
\text { da sessão }\end{array}$ & Presidente & $\begin{array}{c}\text { Verea- Presi- } \\
\text { dora dente }\end{array}$ & $\begin{array}{l}\text { Presi- } \text { Presidente } \\
\text { dente da Junta }\end{array}$ \\
\hline $\begin{array}{l}\text { Condução } \\
\text { da sessão }\end{array}$ & Presidente & Técnicos & Facilitador externo \\
\hline Duração & $3 \mathrm{~h} \quad 1 \mathrm{~h} 30$ & $3 \mathrm{~h}$ & $2 \mathrm{~h} 30$ \\
\hline $\begin{array}{l}\text { N. }{ }^{o} \text { de } \\
\text { parti- } \\
\text { cipantes }\end{array}$ & 64 & 183 & 51 \\
\hline
\end{tabular}

\section{Palmela}

O município de Palmela, um dos 13 municípios pertencentes aos Distrito de Setúbal, tem 62831 habitantes (Censos, 2011), e está dividido em 4 freguesias (correspondendo uma assembleia da freguesia a cada): Palmela, Pinhal Novo, PoceirãoMarateca e Quinta do Anjo. Embora o município seja o menos populoso em estudo, é o que apresenta uma maior dispersão demográfica e geográfica, caracterizando-se os seus $465 \mathrm{~km}^{2}$ por espaços rurais e urbanos. Em Palmela, como aliás na generalidade dos processos de OP, as sessões públicas, a cada ciclo, decorrem, pelo menos uma vez, em cada freguesia. No caso presente, a nossa análise incide sobre a primeira sessão pública observada, que decorreu no Pinhal 
Novo. Esta opção deve-se ao facto de a segunda sessão observada ter sido pouco participada por cidadãos da freguesia, tendo estado presentes, fundamentalmente, funcionários municipais e alguns Presidentes de Junta de Freguesia (primeiro/a candidato/a mais votado/a para a Assembleia de Freguesia) do Município, tendo sido por isso bastante mais curta que a outra sessão analisada, não tendo havido participação de cidadãos nem apresentação de propostas. A sessão em análise decorreu na Sala de Sessões da Junta de Freguesia de Pinhal Novo, que fica a cerca de $10 \mathrm{~km}$ da sede municipal, ilustrando, uma vez mais, a dispersão geográfica que caracteriza a localidade. Estas especificidades podem justificar o investimento que a força política que compõe o executivo camarário há vários anos, a CDU (coligação do Partido Comunista Português e do Partido Os Verdes), tem vindo a fazer em equipamentos sociais de proximidade, e em mecanismos de envolvimento das populações e do movimento associativo local. Por essa razão, o OP neste município tem estado sempre associado ao principal documento de estratégia política local, as Grandes Opções do Plano, GOP (Granado, 2010)². Assim, as populações são envolvidas na elaboração do documento mais importante da estratégia municipal seguida pelo executivo em funções. Trata-se, portanto, de um processo top-down, não partindo da iniciativa popular, mas sim da vontade dos políticos locais, estes de esquerda. Por outro lado, assenta num envolvimento que se cinge ao processo de consulta às populações, não cabendo a estas a decisão final. A sessão observada veio evidenciar esta dimensão. Esta inicia-se com uma longa intervenção do presidente, conforme assinalado na dimensão "papel dos políticos" e "início dos trabalhos" da matriz de observação, que pode ser associado com o que tem sido designado de accountability, ou seja, a prestação de contas por parte do executivo, tornando a sua actividade política o mais transparente possível (Blakeley, 2010). Também, por isso, verifica-se, como assinalado na dimensão "papel dos políticos", por parte do presidente, o uso de uma linguagem essencialmente coloquial, sem recurso a termos técnicos, invocando o carácter democrático da sessão, utilizada também, como já referido, como momento de prestação de contas por parte do executivo. $\mathrm{O}$ espaço físico, ou a arquitectura da escolha, como alguns autores sugerem (Jones, Pykett, \& Whitehead, 2010), analisado através da dimensão "caracterização do espaço", está adaptado ao formato consultivo, organizado em formato de "sala de aula", estando políticos e técnicos sentados de frente para o público (Tabela 2). Esta organização parece não só contribuir para moldar as decisões dos indivíduos (ver Blakeley, 2010; Jones et al., 2010), no sentido em que o formato escolhido tende a valorizar as intervenções dos que se sentam no palanque, e a acentuar a assimetria de poder existente (Jones et al., 2010). Do ponto de vista das intervenções, estas foram poucas e unicamente dirigidas ao executivo, assumindo o formato de "pergunta" ou de "reclamação" relativamente a questões de cariz local ou associativo. De salientar ainda dois aspectos: o uso de expressões como "na minha rua" ou "minha associação" que ilustram o carácter local e associativo das intervenções, havendo um claro foco nos problemas do dia a dia e locais, porventura menosprezados pela "máquina" autárquica, demonstrando também por isso a importância do movimento associativo local, muito representado nesta sessão, funcionando como barómetro da gestão camarária; e o recurso a termos distintivos como nós-vocês, quer pelos políticos, quer pelos cidadãos, ilustrativos das assimetrias de poder (Castro \& Batel, 2008). Na dimensão "interacção na reunião" é de salientar o facto de se verificar o diálogo entre todos os intervenientes, sem grande rigidez na forma de condução da sessão, ainda que com clara preponderância dos membros do executivo municipal, como já descrito anteriormente. Assim, esta sessão de OP em Palmela ilustra como a interacção contextual entre políticos e cidadãos - tanto a material, com base na estrutura e organização do espaço, como a comunicativa - reflectem, reproduzem e fomentam as assimetrias nas relações de poder entre esses grupos (Batel \& Castro, 2009), assentes num modelo de envolvimento do público que é informativo e parcialmente consultivo, e não participativo (Rowe \& Frewer, 2004).

\section{Cascais}

Cascais localiza-se no Distrito de Lisboa, e é o quarto município mais populoso do país (Censos, 2011), tendo mais de 200 mil habitantes numa extensão geográfica relativamente pequena, menos de $100 \mathrm{~km}^{2}$ de área, divididos pelas 4 freguesias: São Domingos de Rana, Carcavelos-Parede, EstorilCascais e Alcabideche. É, portanto, um contexto social e geográfico radicalmente diferente do anterior, não existindo características de ruralidade nem de isolamento populacional que possam explicar o eventual investimento numa governação de maior proximidade com as populações locais. Além disso, Cascais, que se localiza entre a Serra de Sintra e as praias da Costa do Estoril, conhecida por ser uma vila piscatória, caracteriza-se por uma forte componente turística, aliada a uma forte presença de estrangeiros que aí habitam o ano inteiro. O OP de Cascais surge em 2011, por mão da Coligação Viva Cascais (Partido Social-Democrata e Partido 
do Centro Democrático Social), que vê na política de descentralização de competências uma forma de progressiva descentralização de responsabilidades (Dias, 2013). Neste caso, a iniciativa do OP parece revestir-se daquilo que a literatura tem designado de localismo, no sentido em que o governo local promove uma hierarquia centro-local, descentralizando a tomada de decisão política, mas sem abdicar do controlo político do processo (Moir \& Leishon, 2013). As sessões de participação observadas em Cascais pautam-se por ser extremamente estruturadas e com poucos imprevistos. A observação de dimensões como "caracterização do espaço" e "início dos trabalhos" evidencia uma extrema preocupação com a recepção aos cidadãos participantes, o que se manifesta na pensada disposição das salas (Tabela 2) e no cuidado em ter técnicos a receber e a encaminhar os cidadãos, materiais de trabalho para os cidadãos e fornecimento de lanche. A disposição física das salas, nas quais os cidadãos são distribuídos por mesas redondas, parece conforme uma sessão participada e colaborativa, potenciadora da intervenção dos cidadãos (Granado, 2010). Contrariamente ao caso descrito anteriormente, a análise das dimensões já referidas e ainda da "interacção na reunião" permitiu verificar uma interacção entre políticos e cidadãos assente numa maior horizontalidade entre todos os participantes, sendo que apesar da presença de políticos e técnicos nas sessões, estes funcionam como facilitadores do processo, sem aparente influência nas decisões tomadas, não se verificando intervenções assinaláveis ao longo das sessões. O funcionamento das sessões pressupõe igualmente que as decisões tomadas são vinculativas, ficando a câmara comprometida em levar a uma votação final global os projectos aprovados em cada sessão, por isso trata-se de um OP do tipo deliberativo. Pela análise da dimensão do "papel dos técnicos", que são em elevado número, estando espalhados pelas mesas, verificamos que a sua não intervenção ao longo da sessão reforça o carácter colectivo das decisões aí tomadas, não havendo diálogos privilegiados entre determinados intervenientes, criando assim um contexto participativo para a tomada de decisão (Jones et al., 2010), ainda que a presença dos técnicos em cada mesa possa influenciar essas mesmas decisões. Nas sessões observadas, a metodologia adoptada contribui para a simplificação de algo tão complexo como decidir sobre investimentos. Essa simplificação parece dinamizar uma cidadania activa, capaz de se autogovernar, ideia subjacente à política de governo localista (Moir \& Leishon, 2013). Por outro lado, verificámos ainda uma importância exígua da dimensão "papel dos políticos", na medida em que as intervenções foram sempre muito curtas e apenas no início de cada sessão, em jeito de boas vindas. A análise da dimensão "tipo de participação do/a cidadão/a", permite confirmar que o modelo de OP em Cascais promove uma intervenção por parte das populações bem diferente do modelo descrito em Palmela, com intervenções sob a forma de "sugestão/proposta", e não de "pergunta" ou "reclamação". No OP de Cascais, a participação cidadã constitui um efectivo exercício de persuasão por parte das/os cidadãs/ãos (tal como proposto por Lennon \& Scott, 2015), ideia reflectida no facto de haver uma forte presença de bombeiros e de estes terem vindo fardados para as sessões, com o objectivo de realçarem a credibilidade das suas propostas (ethos); na sua capacidade de apresentarem os argumentos da forma o mais estruturada possível (logos), como através do recurso a meios audiovisuais; ou ainda, na capacidade de despertarem emoções na audiência (pathos), invocando realidades próximas dos presentes. Isto revela como, apesar de este OP apresentar um carácter mais deliberativo, ainda assim, e tendo em conta o contexto sócio-histórico e institucional em que os OP se desenvolvem, e especificamente as tradicionais relações de poder entre os sistemas técnico-político e leigo em Portugal (Batel \& Castro, 2009), os cidadãos tendem a recorrer a ferramentas retóricas a fim de legitimar a sua intervenção junto dos sistemas técnico-políticos, especificamente o logos e o ethos (e.g., Batel \& Castro, 2009), o que evidencia a manutenção da assimetria de poder existente. Esta análise parece corroborar a ideia de que, embora os decisores alimentem, na sua interacção com os cidadãos, uma prática discursiva aberta à participação destes, o acentuado controlo da máquina municipal sobre o todo o processo leva-nos a concluir que subjaz ao mesmo uma conceptualização paternalista da participação (Moir \& Leishon, 2013), no sentido em que, embora os cidadãos tenham oportunidade de se pronunciar em determinados momentos, todo o processo é promovido, organizado e tutelado pela Câmara Municipal (ver Knudsen et al., 2015), não havendo a necessária transferência de poder inerente aos processos verdadeiramente participativos (Arnstein, 1969).

\section{Torres Vedras}

O município de Torres Vedras é o município com maior extensão geográfica do Distrito de Lisboa, cerca de $407 \mathrm{~km}^{2}$ de área, caracterizado por uma enorme dispersão demográfica, aliada a uma baixa densidade populacional. Dotada de uma forte componente rural, típica da zona Oeste do país, regiãovinícola privilegiada, Torres Vedras é distribuída por 13 freguesias, entre as quais, Silveira e Torres Vedras-Matacães, cujas 
sessões públicas de participação foram escolhidas para ser observadas para o presente estudo. Do ponto de vista político, Torres Vedras tem sido governada pelo Partido Socialista, de orientação ideológica centro-esquerda. Em 2015, decorre o primeiro OP de Torres Vedras, que surge fortemente associado à Agenda 21, como consta no folheto de divulgação distribuído durante as sessões, reivindicando-se como um OP "verdadeiramente participativo". O OP de Torres Vedras adopta um modelo semelhante ao já descrito para Cascais, por isso, as sessões, designadas assembleias participativas, têm uma organização e um funcionamento idênticos, facto que se verifica ao analisar as dimensões "caracterização do espaço" e "interacção na reunião", nas quais são assinalados itens relativos à recepção feita aos participantes, aos materiais de trabalho fornecidos, à existência de água e rebuçados, bem como a disposição física em mesas de trabalho e espalhadas pelas salas e ainda a identificação dos técnicos com t-shirts específicas do OP. As intervenções dos cidadãos revelaram-se muito semelhantes às observadas em Cascais, assumindo o formato de "sugestão/proposta", ou "esclarecimento". Na dimensão "início dos trabalhos" assinalámos o facto de as sessões serem dinamizadas por um facilitador externo. É difícil perceber, a partir das observações realizadas, qual o grau de proximidade que existe entre a Câmara Municipal e os cidadãos do município em análise, no entanto, o recurso a intermediários e/ou facilitadores externos na implementação de projectos inovadores, como é o caso do OP em Torres Vedras, tem sido estudado pela literatura (e.g., DevineWright, 2012). Vários autores têm considerado o papel destas terceiras partes, ou entidades externas, como promotores das oportunidades de cidadãs/ãos não organizados participarem no debate público e na agenda política (Devine-Wright, 2012). Por outro lado, tem sido discutido em que medida a introdução de um moderador, sem relação alguma com as comunidades, pode ser vista por estas com suspeição e falta de confiança (ver Devine-Wright 2012; Knudsen et al., 2015). Neste OP, o moderador das sessões era um professor universitário, com investigação na área da participação e do desenvolvimento sustentável. Tais factos vieram conferir à sessão uma credibilidade e cientificidade inquestionável pelo público presente - recursos a meios audiovisuais e apresentação de estudos científicos - numa evidente construção retórica da credibilidade, com uma abordagem do tipo logos (Lennon \& Scott, 2015); por outro lado, ao ser responsável pelas sessões, o potencial de conflito, perante a novidade do processo, está entregue ao facilitador externo (van Lente, Hekkert, Smits, \& van Waveren, 2003). Este OP, aparentemente participativo, assente numa organização espacial promotora da participação cidadã, padece, no entanto, de constrangimentos semelhantes aos descritos para Cascais, em particular a relação desigual que se estabelece entre os intervenientes (Barry et al., 2008) aos cidadãos cabe participar no estrito quadro definido pela Câmara Municipal e pelo facilitador externo. Na tabela 3 sistematizamos os principais resultados para cada município, nomeadamente ao nível do modelo de OP implementado.

Tabela 3. Principais resultados para cada município

\begin{tabular}{|c|c|c|c|}
\hline & Palmela & Cascais & Torres Vedras \\
\hline $\begin{array}{r}\text { Auto- } \\
\text { classificação } \\
\text { de modelo de } \\
\text { decisão. Tipo } \\
\text { de modelo } \\
\text { de decisão } \\
\text { observado. } \\
\text { Tipo de } \\
\text { processo. }\end{array}$ & $\begin{array}{l}\text { Consultivo. } \\
\text { Consultivo. } \\
\text { Não é } \\
\text { verdadeira- } \\
\text { mente } \\
\text { participativo. }\end{array}$ & $\begin{array}{c}\text { Deliberativo. } \\
\text { Deliberativo. } \\
\text { Não é } \\
\text { verdadeira- } \\
\text { mente } \\
\text { participativo. }\end{array}$ & $\begin{array}{l}\text { Deliberativo. } \\
\text { Deliberativo. } \\
\text { Não é } \\
\text { verdadeira- } \\
\text { mente } \\
\text { participativo. }\end{array}$ \\
\hline $\begin{array}{r}\text { Disposição } \\
\text { física da sala }\end{array}$ & $\begin{array}{c}\text { Formato } \\
\text { formal/ } \\
\text { consultivo } \\
\end{array}$ & $\begin{array}{c}\text { Formato } \\
\text { informal/ } \\
\text { deliberativo } \\
\end{array}$ & $\begin{array}{c}\text { Formato } \\
\text { informal/ } \\
\text { deliberativo } \\
\end{array}$ \\
\hline $\begin{array}{l}\text { Intervenções } \\
\text { dos cidadãos }\end{array}$ & $\begin{array}{c}\text { Perguntas ou } \\
\text { reclamações; } \\
\text { menos } \\
\text { tempo de } \\
\text { intervenção; } \\
\text { intervenções } \\
\text { mais locais e } \\
\text { individualistas }\end{array}$ & $\begin{array}{l}\text { Sugestões; } \\
\text { mais tempo de } \\
\text { intervenção; } \\
\text { intervenções } \\
\text { mais globais }\end{array}$ & $\begin{array}{l}\text { Sugestões; } \\
\text { mais tempo de } \\
\text { intervenção; } \\
\text { intervenções } \\
\text { mais globais }\end{array}$ \\
\hline $\begin{array}{l}\text { Intervenções } \\
\text { dos políticos }\end{array}$ & $\begin{array}{c}\text { Mais tempo de } \\
\text { intervenção }\end{array}$ & $\begin{array}{l}\text { Menos tempo } \\
\text { de intervenção }\end{array}$ & $\begin{array}{c}\text { Sessões } \\
\text { conduzidas por } \\
\text { intermediários }\end{array}$ \\
\hline $\begin{array}{r}\text { Mecanismos } \\
\text { retóricos } \\
\text { cidadãos } \\
\end{array}$ & Nós vs. Eles & $\begin{array}{c}\text { Ethos, logos, } \\
\text { pathos } \\
\text { Nós vs. eles } \\
\end{array}$ & $\begin{array}{c}\text { Ethos, logos, } \\
\text { pathos } \\
\text { Nós vs. Eles } \\
\end{array}$ \\
\hline $\begin{array}{r}\text { Mecanismos } \\
\text { retóricos } \\
\text { políticos } \\
\end{array}$ & Nós vs. Eles & Nós vs. eles & Nós vs. Eles \\
\hline $\begin{array}{r}\text { Contexto } \\
\text { socio- } \\
\text { institucional }\end{array}$ & $\begin{array}{c}\text { Carácter } \\
\text { consultivo } \\
\text { do OP } \\
\text { mas outras } \\
\text { iniciativas } \\
\text { locais de } \\
\text { participação } \\
\text { da } \\
\text { população } \\
\text { (e.g., (A) } \\
\text { gente do } \\
\text { bairro; Eu } \\
\text { participo!); } \\
\text { OP de } \\
\text { carácter } \\
\text { mais } \\
\text { ideológico }\end{array}$ & $\begin{array}{c}\text { Carácter } \\
\text { deliberativo } \\
\text { do OP mas } \\
\text { ausência } \\
\text { de outras } \\
\text { iniciativas } \\
\text { locais de } \\
\text { participação; } \\
\text { OP de carácter } \\
\text { mais ideológico }\end{array}$ & $\begin{array}{c}\text { Carácter } \\
\text { deliberativo } \\
\text { do OP mas } \\
\text { ausência } \\
\text { de outras } \\
\text { iniciativas } \\
\text { locais de } \\
\text { participação; } \\
\text { OP de carácter } \\
\text { mais científico/ } \\
\text { mais ligado } \\
\text { com objectivos } \\
\text { de Agenda } 21\end{array}$ \\
\hline
\end{tabular}




\section{Conclusões}

Este estudo pretendeu contribuir para uma melhor compreensão dos factores estruturais, ideológicos e contextuais-relacionais associados à participação das/ os cidadãs/ãos com base numa análise exploratória do funcionamento dos OP em 3 municípios em Portugal. Em Palmela, o OP não constitui o principal instrumento do envolvimento dos cidadãos. No entanto, é neste município que começam as experiências de OP em Portugal (Granado, 2010), havendo uma experiência de participação por parte do município, que se verifica na proliferação de outros mecanismos participativos (e.g. Agente do Bairro) e, provavelmente, que explica a lotação de algumas sessões públicas de OP, apesar da antiguidade do processo nesta região, e de os cidadãos saberem, de antemão, que não serão deliberativas. $\mathrm{O}$ que parece atrair os cidadãos para o processo de OP neste município não é tanto a possibilidade de participar na tomada de decisão, mas a continuidade de uma relação de transparência e de proximidade entre os políticos e os cidadãos desta região. Em Cascais e Torres Vedras - ainda que sobre este último seja mais difícil avaliar dada a novidade do OP - o OP parece ser o principal instrumento da governação local, de cariz participativo. Talvez por isso se verifique um investimento tão significativo por parte, sobretudo, dos técnicos municipais, para garantir que todas as fases do processo decorram com a máxima eficácia e sem imprevistos. Em comparação com o $\mathrm{OP}$ de Palmela, nestes dois municípios, o OP parece emergir de uma visão da participação como nova forma de responsabilização política, na qual os eleitos deixam de ser os únicos responsáveis pela decisão política (Blakeley, 2010; Moir \& Leyshon, 2013). No entanto, a aparente partilha de decisões entre quem elege e quem é eleito (Jones et al., 2010) é, rapidamente, contrariada pela realidade, pois verifica-se que permanece na esfera exclusiva da Câmara a decisão sobre os montantes em causa e a organização do processo do OP (Knudsen et al., 2015). Assim, o formato deliberativo dos OP em Cascais e Torres Vedras, e a aparente autonomia dos cidadãos para escolher e decidir (Swyngedouw, 2010), não parece ter resultados diferentes dos obtidos através de um formato do tipo consultivo, como o de Palmela, no sentido em que em ambos se verifica não haver qualquer ameaça à relação hierárquica entre o Estado/câmara e a sociedade/cidadãos locais (Moir \& Leishon, 2013). Esta constatação permite concluir que nem sempre a participação pública está associada a mais cidadania e mais democracia, se considerarmos que a verdadeira participação é sempre acompanhada de perda de poder (Arnstein, 1969), e que, para tal, é necessário que os tradicionais decisores e os cidadãos estejam em pé de igualdade. Ou seja, quer modelos deliberativos, quer consultivos de OP, em Portugal, parecem perpetuar formas tradicionais e personalistas de legitimação política (Granado, 2010), o que transforma estes processos em instrumentos de abrandamento da democracia (Swyngedow, 2010). Tal parece ilustrar bem a ideia de que

Portugal não tem ... tradição de participação pública, numa base institucional $\ldots$ a cultura política portuguesa favorece mais o exercício da autoridade, do que a procura das bases científicas das decisões políticas ou um diálogo aberto e pluralista com os grupos de interesse e movimentos sociais". (Gonçalves, 2000, p.157)

Este estudo por observação foi só exploratório e não permitiu aprofundar o que cidadãos/ãs, técnicos e políticos pensam sobre estas formas de institucionalização da participação, nem de que forma as relações de poder que se estabelecem entre os vários intervenientes no processo de participação podem influenciar a participação dos/as cidadãos/ãs. Assim, seria importante, no futuro, examinar o que pensam os vários actores envolvidos num processo institucional de participação sobre as suas diferentes componentes, designadamente, através dos discursos que os mesmos produzem sobre formas institucionais de participação, como o orçamento participativo. Contudo, este trabalho contribui de forma relevante para a literatura da Psicologia Social e Ambiental sobre a participação institucional, não só ao explorar este tipo de participação - que tem vindo a ser negligenciado por essa literatura - mas também ao ilustrar dois aspectos importantes. Por um lado, que compreender os factores associados à participação implica ter em conta o seu contexto histórico, cultural e político e, por outro lado, que é na interacção em contextos específicos entre políticos, técnicos e cidadãos que as relações de poder assimétricas entre estes grupos se perpetuam, constrangendo a participação - mas também que esses são espaços em que essas relações de poder podem, eventualmente, ser contestadas.

\section{Notas}

1 São minoritários no contexto aqui discutido, isto é, da Psicologia Social mainstream, nomeadamente baseada nos modelos desenvolvidos em contexto anglo-saxónico (Farr, 1996). No entanto, importa referir que noutros contextos, como na América Latina, são prolíficas as análises críticas de movimentos sociais e participação institucional (e.g., Avritzer, 2003; Campbell \& Jovchelovitch, 2000; Nelson \& Prilletensky, 2005).

2 Granado, C. (2010). Democracia e participação ao nível local: o poder político e o orçamento participativo. $O$ caso de Belo Horizonte e Palmela. Tese de Doutorado, não publicada, ISCTE-IUL, Lisboa. 


\section{Referências}

Agenda 21. (1992). Report of the UN Conference on Environment and Development. Recuperado de http://www. unesco.org/education/nfsunesco/pdf/RIO_E.PDF

Allegretti, G. \& Dias, N. (2009). Orçamentos participativos em Portugal: em busca de uma democracia de maior proximidade ou de uma racionalidade funcional? Cidades. Comunidades e Territórios, 18, 59-78.

Arnstein, S. (1969). The ladder of participation. Journal of the American Institute of Planners, 35(4), 216-224.

Avritzer, L. (2003). Modelos de deliberação democrática: uma análise do orçamento participativo no Brasil. In B. S. Santos (Org.), Democratizar a democracia: os caminhos da democracia participativa (pp. 561-598). Porto, PT: Afrontamento.

Bakeman, R. (2000). Behavioral observation and coding. In H. T. Reis \& C. K. Judd (Eds.), Handbook of research methods in social psychology (pp. 138 -159). New York: Cambridge University Press.

Barnett, J., Burningham, K., Walker, G., \& Cass, N. (2012). Imagined publics and engagement around renewable energy technologies in the UK. Public Understanding of Science, 21, 36-50.

Barry, J., Ellis, G., \& Robinson, C. (2008). Cool Rationalities and Hot Air: A Rhetorical Approach to Understanding Debates on Renewable Energy. Global Environmental Politics, 8(2), 67-98.

Batel, S. \& Castro, P. (2009). A social representations approach to the communication between different spheres: An analysis of the impacts of two discursive formats. Journal for the Theory of Social Behaviour, 39(4), 415-433.

Batel, S. \& Castro, P. (2015). Collective action and social change: examining the role of representation in the communication between protesters and third-party members. Journal of Community \& Applied Social Psychology, 25(3), 249-263.

Batel, S. \& Devine-Wright, P. (2015). Towards a better understanding of people's responses to renewable energy technologies: Insights from Social Representations Theory. Public Understanding of Science, 24, 311-325.

Blakeley, G., (2010). Governing ourselves: citizen participation and governance in Barcelona and Manchester. International Journal of Urban and Regional Research, 34(1), 130-145.

Campbell, C. \& Jovchelovitch, S. (2000). Health, community and development: Towards a social psychology of participation. Journal of Community and Applied Social Psychology, 10(4), 255-270.

Cass, N. (2006). Participatory-Deliberative Engagement: a literature review. Working Paper 1.2. Manchester: School of Environment and Development. Recuperado de http://www. manchester.ac.uk/sed/research/beyond_nimbyism

Castro, P. \& Batel, S. (2008). Social representation, change and resistance: on the difficultiesof generalizing new norms. Culture \& Psychology, 14(4), 477-499.

Censos (2011). Censos 2011 Resultados Definitivos. Portugal Instituto Nacional de Estatística. Recuperado de http://censos.ine.pt/xportal/ xmain? $x$ pid $=$ CENSOS\&xpgid=ine_censos_publicacao det $\&$ contexto=pu\&PUBLICACOESpub_boui $=73212$ $469 \&$ PUBLICACOESmodo $=2 \&$ selTab $=$ tab $1 \&$ pcens os $=61969554$
Colander, D. \& Qui Lin Chong, A. (2009). The Choice Architecture of Choice Architecture: Toward a Nonpaternalistic Nudge Policy. Discussion Paper n. 1036, Middlebury College Economics. Vermont: Middlebury College.

Devine-Wright, P. (2012). Fostering public engagement in wind energy development: the role of intermediaries and community benefits. In J. Szarka, R. Cowell, \& G. Ellis (Eds.), Learning from Wind Power (pp. 194-214). Basingstoke, UK: Palgrave Macmillan.

Dias, N. (Coord.). (2013). Esperança democrática: 25 anos de orçamento participativos no mundo. Lisboa: Associação In Loco.

Elcheroth, G., Doise, W., \& Reicher, S. (2011). On the knowledge of politics and the politics of knowledge: How a social representations approach helps us rethink the subject of political psychology. Political Psychology, 32(5), 729758.

Farr, R. M. (1996). The roots of modern social psychology, 1872-1954. Oxford, UK: Blackwell Publishing.

Gonçalves, M. E. (Org.). (2000). Cultura cientifica e participação pública. Oeiras, PT: Celta.

Gonçalves, M. E. \& Castro, P. (2003). Science, culture \& policy in Portugal: a triangle of changing relationships. Portuguese Journal of social Science, 1(3), 157-173.

Jones, R., Pykett, J., \& Whitehead, M. (2010). Governing temptation: Changing behaviour in an age of libertarian paternalism. Progress in Human Geography 35(4), 483-501.

Knudsen, J., Wold, L. C., Aas, O., Haug, J. J. K., Batel, S., Devien-Wright, P., Qvenild, M., \& Jacobsen, G. B. (2015). Local perceptions of opportunities for engagement and procedural justice in electricity transmission grid projects in Norway and the UK. Land Use Policy, 48, 299-308.

Latour, B. (2005). Reassembling the Social: an introduction to Actor Network Theory. Oxford, UK: Oxford University Press.

Lennon, M. \& Scott, M. (2015). Contending Expertise: An Interpretive Approach to (Re)conceiving Wind Power's 'Planning Problem'. Journal of Environmental Policy \& Planning, 17(5), 593-616.

Marres, N. (2012). Material Participation: Technology, The Environment and Everyday Publics. Basingstoke, UK: Palgrave Macmillan.

Martins, C. \& Machado, C. (2006). Observação da interação humana: Considerações metodológicas. Psicologia: Teoria, Investigação e Prática, 11(2), 159-175.

Moir, E. \& Leyshon, M. (2013). The design of decision-making: participatory budgeting and the production of localism, Local Environment. The International Journal of Justice and Sustainability, 18(9), 1002-1023.

Mouffe, C. (2013). Agonistics: Thinking The World Politically. New York: Verso.

Nelson, G. \& Prilletensky, I. (2005). Community Psychology: In Pursuit of Liberation and Well-being. Basingstoke, UK: Palgrave MacMillan.

Nunes, C. (2011). Expressões Alterglobais na Sociedade Portuguesa: Ecos Transnacionais de Novas Formas de Acção Colectiva? Working Paper CIES n. 104/2011.

Pina-Cabral, J. (2009). The all-or-nothing syndrome and the human condition. Social Analysis, 53(2), 163-176.

Rowe, G. \& Frewer, L. J. (2004). Evaluating public-participation exercises: a research agenda. Science, technology evaluating \& human values, 29(4), 512-566. 
Santos, B. S. (1998). O Estado e a sociedade em Portugal (1974-1988). Porto, PT: Edições Afrontamento.

Serapioni, M. \& Duxbury, N. (2012). Citizens' participation in the Italian healthcare system: the experience of the Mixed Advisory Committees. Health Expectations, 17, 488-499.

Swyngedouw, E. (2010). Apocalypse forever? Post-political populism and the spectre of climate change. Theory, Culture \& Society, 27(2-3), 213-232.

Thaler, R. \& Sunstein, C. (2008). Nudge, Improving Decisions About Health, Wealth, and Happiness. New Haven;London: Yale University Press.

van Lente, H., Hekkert, M., Smits, R., \& van Waveren, B. (2003). Roles of systemic intermediaries in transition processes. International journal of Innovation management 7(3), 247-279.

van Stekelenburg, J., Klandermans, B., \& van Dijk, W. (2009). Context matters: Explaining how and why mobilizing context influences motivational dynamics. Journal of Social Issues 65(4), 815-838.

van Zomeren, M., Postmes, T., \& Spears, R. (2008). Toward an integrative social identity model of collective action: A quantitative research synthesis of three socio-psychological perspectives. Psychological Bulletin, 134, 504-535.

Zuber, I. (2010). Trabalho etnográfico na cidade de Caracas: questões metodológicas. CIES e-Working Paper, n. 89/2010, Lisboa: CIES-IUL.

Submissão em: 24/06/2016

Revisão em: 11/09/2017

Aceite em: 02/10/2017

Agências de fomento: Fundação para a Ciência e a Tecnologia - FCT/Portugal - bolsa de doutoramento concedida à primeira autora [SFRH/ BD/80769/2011], bolsa de investigação de pósdoutoramento concedida à segunda autora [SFRH/ BPD/96061/2013]. Centro de Investigação e Intervenção Social (Cis-IUL, ISCTE-IUL - Ref. UID/ PSI/03125/2013).
Margarida Santos é doutoranda em Psicologia no Centro de Investigação e Intervenção Social, do Instituto Universitário de Lisboa (Cis, ISCTE-IUL). A sua investigação centra-se sobretudo num mecanismo específico de participação institucional - o orçamento participativo - e em que medida esta institucionalização pode explicar a (falta de) participação pública em Portugal.

Endereço para correspondência: Centro de Investigação e Intervenção Social, Cis/ISCTE-IUL, Sala 2N6. Avenida das Forças Armadas, 1649-026, Lisboa, Portugal. E-mail: margarida.tpc@gmail.com

Susana Batel é investigadora integrada no Centro de Investigação e Intervenção Social, do Instituto Universitário de Lisboa (Cis, ISCTE-IUL), com uma bolsa atribuída pela Fundação para a Ciência e Tecnologia. A sua investigação parte de uma perspectiva crítica para estudar a relação entre representação, identidade, poder, discurso e comunicação, e a mudança social, nomeadamente, a participação pública em questões ambientais e face às energias renováveis e tecnologias relacionadas. É coeditora da revista Papers on Social Representations.

E-mail: susana.batel@iscte.pt

Maria Eduarda Gonçalves é professora catedrática em Direito no ISCTE - Instituto Universitário de Lisboa e investigadora integrada no DINÂMIA'CET - Centro de Estudos sobre a Mudança Socioeconómica e o Território, no ISCTE-IUL. Foi diretora deste Centro entre 2013 e 2016. A sua investigação tem estado centrada sobretudo em ciência, tecnologia e direito e a regulação do risco no contexto europeu.

E-mail: maria.eduarda.goncalves@iscte.pt 